\title{
HENDRIK DE COCK EN ART. 29 NGB (2)
}

\author{
Dr. C. v. d. Waal (Pretoria)
}

Op 'n vraag of die Hervormde Kerk valse kerk of minder suiwere kerk is, antwoord $\mathrm{K}$. Dijk:

„Hendrik de Cock en de zijnen spraken van een valse kerk, omdat zij zagen op het instituut, dat de zuivere prediking van het Evangelie niet verdroeg en de Afgescheidenen uitwierp en vervolgde; ik zou de H. K. van heden niet graag een valse kerk noemen; een valse kerk is geen kerk meer; haar verrichtingen zijn geen kerkacties meer; zij kan ook niets meer ambtelijk doen; er kan ook geen sprake zijn van ambtelijke sacramentsbediening; de H.K. is m.i. kerk, al is ze in haar leervrijheid en onvoldoende tuchtoefening op de verkeerde weg; wilt ge dit minder-zuiver noemen? Ik hecht niet bijzonder aan deze term; ik spreek liever van gereformeerd, en bepaal dan niet verder de verschillende graden". (Gereformeerd Jongelingsblad, 21.7.1948). Dijk kyk met 'n Kuyperiaanse bril en lees latere standpunte eenvoudig in vroeëre formuleringe in. Die historie word dan op hierdie manier ,her-interpreteer' - 'n gevaar vir ons Afrikaanse geskiedskrywing.

Dijk stel dat Hendrik de Cock hom van die Hervormde instituut afgeskei het en dit ,valse kerk' genoem het. Die werklikheid is egter anders. De Cock het hom nie net van die instituut, die organisasie, die sinode afgeskei nie, maar van die Hervormde Kerk as sodanig en dit ,valse kerk' genoem, hoewel hy wel deeglik geweet het dat daarin baie kinders van God was. Die Akte van Afskeiding beweer dat ,het Nederlandsche Kerkbestuur' hom soos, de door onze Vaderen verworpene Paapsche kerk' openbaar het. Dit is die groot beslissing wat tot Afskeiding lei. Soos die Reformasie opgekom het teen die leuse van Rome: ons word nooit 'n sinagoge van die satan nie! ,so het die Afskeiding aangestorm teen dieselfde hoogmoed van die liberale Hervormde Kerk. De Cock het openlik die Hervormde Sinode gelykgestel met die sanhedrin, die sinagoge, die Roomse kerk en die pouselike bestuur.

Teen die argument dat die ware kerk onsigbaar is, het De Cock hom beroep op art. 29 en gewys op die drie kenmerke van die ware kerk. Het Guido de Bres sy lewe gegee vir 'n saak wat vaag en ongrypbaar is? „Wie ijst niet van zulk een Liberaalheid? En hoe druischt het niet aan, tegen den zin, de meening en het voorschrift van geheel onze Geloofsbelijdenis, dan immers behoefde er in het geheel geene Geloofsbelijdenis te wezen, veel minder de kenteekenen der ware kerk te worden opgegeven, gelijk geschiedt art. 29".

De Cock stel tereg dat die in art. 29 genoemde kenmerke van die valse kerk nie slegs op die Roomse Kerk slaan nie as op enige ander valse kerk.

De Cock hef soos Calvyn teenoor Sadoletus weer die banier van die Belydenis op en roep op tot afskeiding. Hy weet terdeë dat baie van die volk van Gods nog hulle onder die sinodale juk bevind. Juis daarom handhaaf hy die aktuele plig tot afskeiding. "Zulke menschen nu roept hier onze Belydenis toe: Gij moogt $u$ 
niet op $u$ zelven houden, maar gij zijt schuldig $u$ bij de ware kerk te voegen en $u$ daarmede te vereenigen, en geen uitvlugt maken, dat gij er inwendig meer vereenigt zij, neen, gij moet er $u$ bijvoegen, want daar staat geschreven: die niet met mij is, is tegen mij, die niet met mij vergadert die verstrooit". (Hierdie sitate is met bronvermelding te vinde in: C. van der Waal, Antithese of Synthese? ,Enschede 1951, p. 344-349).

Uit die Argiefstukke van die Afskeiding toon duidelik dat hierdie mening van De Cock gemeengoed by die Afgeskeidenes was. Ondanks interne moeilikhede het dit hulle gesterk en het die Afskeiding enorm gegroei van 8000 in 1838 tot 150000 in 1880. Hulle het met die Belylenis in die hand die valse kerk aangewys. ' $n$ Geslag later kan mens dit simplisties noem. Dit was egter die feite.

Ons konstateer ook dat die latere mening van Kuyper dat die valse kerk eintlik 'n kerk is waar satan woon en waar eintlik geen kerkvorm meer aanwesig is nie, nie by De Cock aangewys kan word nie.

\section{Postma en Art. 29 NGB}

Postma was 'n baie gesiene figuur in die Afgeskeie Kerk. Hy het gedien op (die moderamen van) sinodes. As sodanig het hy ook in 1851 onderhandel met $\mathrm{A}$. Brummelkamp wat met sy Gelderse kerke tydelik van die hoofmoot van die Afgeskeidenis geỉsoleer was. Postma het hierin in 'n kommissie saam met prof. T. F. de Haan en ds. G. F. Gezelle Meerburg gewerk. In die, Verslag van de Synode der Christelijk Afgescheidene Kerk in Nederland, gehouden van den 23sten April tot den 1sten Mei 1851 te Amsterdam' kan mens uivoerige mededeling oor die onderhandelings vind (p. 5-18). In daardie dae was die styl van die Handelinge nog nie so klerkagtig en notariëel soos vandag nie, maar amper kinderlik -naief en vroom. Jy kyk reg in die harte. Diskussies word op prettige manier weergegee met die oog op lede en belangstellendes. Sitate sou laat blyk hoe die broeders christelik met mekaar omgegaan het sonder om soetlik te word.

Die Sinode en Brummelkamp het in verband met art. 28 NGB verskil. Ds. Brummelkamp het steeds streng afskeiding van die Bestuur en afskeiding van die genootskap van die Hervormde Kerk onderskei (vgl later Doleansie-standpunt van A. Kuyper) en die doleansie van die Kontra-Remonstrante voor 1618, Verslag p. 15).

Predikante F. A. Kok, G. F. Gezelle Meerburg en D. Postma moes die besluit van die sinode formuleer. Dit is in die Verslag opgeneem. Ons siter enkele gedeeltes wat in die Afrikaanse kerkgeskiedenis te min aandag gekry het: „Ds. Brummelkamp verklaarde daarenboven nog, zich nooit van het Hervormd Genootschap, maar wel van het onwettige Kerkbestuur te hebben afgescheiden, en dat hij daarom zich verplicht acht met degenen, die zich nog in dat Kerkgenootschap bevinden, zamen te moeten werken, ware het mogelijk, om het onwettige Kerkbestuur, hetwelk ZEw. ende een dievenbestuur te zijn, dat was ingedrongen, krachteloos te maken, en alzoo de Hervormde Kerk, ware het momelijk, te herstellen zoo als dezelve was voor 1816. 
„Ten aanzien van het Kerkelijke standpunt tegenover dat van Ds. Brummelkamp c.s. verklaart de Synode: dat zij zich, overeenkomstig Art. 28 onzer Geloofsbelijdenis, heeft afgescheiden van de Hervormde Kerk, omdat deze de kenmerken van de ware Kerk van Christus heeft verloren.

"Uit het bovenstaande is het onderscheiden standpunt duidelik. Wij gelooven, door Gods vrije en ontfermende genade, overeenkomstig des Heeren Woord 2 Kor. $6: 17$, in verband met Openbaring $18: 4:$,daarom gaat uit het midden van hen en scheidt $u$ af, zegt ek Heere, en raakt niet aan hetgene onrein is, en ik zal u aannemen", verwaardigd te zijn geworden om een Kerkgenootschap te verlaten, hetwelk het kenmerkende van de ware Kerk geheel heeft verloren; ofschoon er ook sommige Predikanten in zijn, die betuigen, de Gereformeerde leer in alle hare stukken en deelen aan te nemen, en die trachten df' Kerk in de Kerk te herstellen, welk herstel onzes erachtens even onmogelijk is als in de tijden der Reformatie, omdat de fondamenten van onze Gereformeerde Kerk dààr zijn weggenomen. (Fomdamenten; verg. ,Fondeert', ,grondt' in die slot van art. 29 NGB; v.d.W.).

"Indien wij dit in gemoede voor den Heere niet geloofd hadden, dan hadden wij ons, overeenkomstig onze formulieren van eenig. heid, niet mogen afscheiden, en zouden derhalve ons togenwoordig standpunt moeten verloochenen, hetwelk door ons bij dezen niet mogelijk is, omdat wij van harte gelooven, dat de Heere JEZUS, als Koning der Kerk, Zijn volk gelieft uit te leiden".

Aan hierdie klassieke stuk is die handtekening van Postma verbonde. Ds. Joffers het sterk teen Brummelkamp gestaan. Brummelkamp het saam met Da Costa in Amsterdam 'n Christelijk Gereformeerd Seminarie in ,interkerklike samewerking' beoog. Dit het hom laat dink dat hy hom net van die Bestuur en nie van die Hervormde Kerk as sodanig afgeskei het nie. Hy het hom in 1854 met die Chr. Afg. Kerk verenig, hoewel hy altyd insake die kerk nie sterk standpunt ingeneem het nie. Postma het hom nie met Brummelkamp se ,Doleansie'-beskouing verenig nie.

Dit is merkwaardig dat G. C. P. van der Vyver in sy Professor Dirk Postma slegs op p. 120 drie sinne aan die 1851-sinode wy en hierdie belangrike verklaring nie siteer nie. Hy behandel elders ( $p$. 140-147) Postma se beskouings oor die, afskeiding van die valse kerk'. Hy konkludeer op grond van Postma se latere gedrag in Transvaal wat sy houding in Nederland ten aansien van die Hervormde Kerk sou wees. Van der Vyver wil 'n uitspraak in 1852 dat elkeen wat met oordeel begaafd is, moet saamstem dat die teenwoordige Hervormde Kerk 'n valse kerk is, van Postma losmaak. Hy sê selfs "dat hy ten opsigte van hierdie saak, van die vaders van die Afskeiding verskil het, wat in 1834 die Hervormde Kerk van Nederland sonder meer as valse kerk verklaar het". Hy vervolg: „Indien hy nie verskil het nie, was hy ten minste in sy gemoed nie ten volle oortuig van die goeie reg van sodanige uitspraak oor die Hervormde Kerk nie. Dat Postma by 'n Afskeiding die kerk wat verlaat word, nie noodwendig ' $n$ valse kerk beskou nie, word verder bewys deur 
sy latere standpunt oor die probleem „waar-vals” by die Afskeiding in Suid-Afrika" (p. 142).

In die lig van die 1851-verklaring op die sinode kan bowestaande bewerings van Van der Vyver nie aanvaar word nie. Hy verwys na die feit dat later in gereformeerde kringe met voorbehoud gespreek is oor die Hervormde Kerk as 'n valse kerk (p. 142, 143, noot 48). Dit is ongetwyfeld waar vanweë die invloed van A. Kuyper na wie se Tractaat van de Reformatie der Kerk (Amsterdam 1884, p. 195-199) Van der Vyver Via L. Praamsma, Het Dwaze Gods, p. 93 nadruklik verwys. Dit is ongeoorloof om vanuit die Kuyper-visie die optrede van Postma voor sy vertrek na Suid-Afrika te beoordeel. Dit bring 'n vertekende en geparfumeerde kerkhistorie mee.

\section{Postma se optrede in Suid-Afrika.}

Sy vertrek na Transvaal het nie die (her-)stigting van 'n kerk ten doel gehad nie. Hy was na Transvaal afgevaardig om ,op de plaats zelve onderzoek te doen naar den godsdienstigen toestand van onze stamverwanten en geloofsgenoten aldaar, broederlijke betrekkingen met hen aan te knopen en in alles te handelen gelijk het homzelven het nuttigst zal voorkomen in het belang van Gods Koninkrijk en van onze stamverwanten en geloofsgenooten op Zuid-Afrika's Oostkust" (Van den Vyver, p. 170, sy lasbrief).

Postma het self sy afvaardiging ook in verband gebring met die moontlikheid dat ,Eene deur des Evangelies tot de Heidenen' geopen sou word (Van der Vyver, p. 171). Die Sinodale Kommissie wat hom afgevaardig het, het verklaar dat die keuse op hom geval het omdat hy iemand was, die het vertrouwen der kerk bezit, met haren toestand en met de redenen onzer afscheiding van het Hervormde Kerkgenootschap volkomen bekend, ten einde ginds een duidelijk verslag van zaken te kunnen geven' (Van der Vyver, p. 167 kursivering van v.d.W.). Hieruit blyk duidelik dat van Postma verwag is dat hy op die standpunt van die Afskeiding ooreenkomstig art. 29 NGB sou staan en nie op dié van Ledeboer (en tydelik ds. Brummelkamp) nie. Die sending van Postma het in die teken gestaan van 'n sekere ekspansie-drang van die groeiende Afgeskeie Kerk in Nederland.

Die afvaardiging van Postma het daarop uitgeloop dat hy op 11 Februarie 1859 die herderstaf opneem van die (vrije) Gereformeerle Kerk in de Zuid-Afrikaansche Republiek. Dit het in Nederland vrae opgeroep. Op 1 September 1899 skryf die Sinodale Kommissie uit Nederland om nadere inligting. Uit sy rapport word opgemaak dat die Hervormde Kerk van Transvaal nie die ware kerk is nie, maar ook dat Postma dit nie kaalkop sê nie. Ook is daar vrae betreffende Postma se voorgaan in Hervormde dienste.

Postma antwoord op 3 Desember 1859 dat die Hervormde Kerk ,eigengoeddunken' bo die Bybel stel. Om die Hervormde Kerk ,nu echter in statu quo voor eene valsche Kerk te verklaren, daartoe voelen wij ons nog niet geroepen. Gaat zij zoo voort, dan zeker zal dat karakter niet uitblijven, maar duidelijk voor den dag treden. Maar nu toonen wij nog maar altoos aan dat zij dwaalt en waar- 
schuwen voor ergere gevolgen. Doch al wat ik te dien opzichte doe, moet geschieden met veel voorzichtigheid, met het oog op hunne weinige ontwikkeling, alsmede met het oog op hunnen leidsman". Ons mag hier nie te veel uit aflei nie. Postma bedoel: daar is nog min kennis onder die mense ten opsigte van die Afskeiding in Nederland. Boonop is alles nog vloeibaar. Onmiddellike ,valse kerk' tipering sou so vrees hy, 'n onnodige breuk slaan. En dan volg die wyse woorde wat vir die Afgeskeidenes in de vorige eeu net so moeilik was om te sluk as tans vir Nederlandse vrygemaaktes-binne-die verband: „Men moet hier zijn om de zaak in de omstandigheden te kunnen beoordelen. Gelooft mij, dat ik in dezen weg meer dan gewone wijsheid van boven noodig heb en mij gedurig daaraan diep behoeftig gevoel".

Die aandrang van Nederland om hom duideliker uit te spreek, het daartoe gelei dat op die Sinode van die GKSA 'n openbare verklaring, 'n laat „Akte van Afskeiding", ,ten behoewe van hare moederkerk" in Nederland aanvaar is. Hierdie Openbare Verklaring wat allereers in 1869 vir eksport bestem was, is in 1942 tydens die Tweede Wêreldoorlog feitlik oornag opgehef. Die tyd dat dit in die uitgawe van die Kerkorde as Bylae (tot 1931-uitgawe) opgeneem is, lê reeds ver agter ons.

Die verklaring hef aan met: ,En nog meer heeft de Synode het nuttig geoordeeld voor ons eigen nakroost, dat deze verklaring gegeven worde door mannen, die zelven voorgangers bij de afscheiding geweest zijn'. Dit wou 'n nadere motivering van die afskeiding van 1859, gedagtig aan Ps. $78: 4$ (ber.), wees.

Jooste merk iewers op dat Postma te min gemotiveerd berigte na Nederland deurgegee het. Hy kon hom baie moeite bespaar het. Die ,Openbare Verklaring' wou die gemaakte foute regstel. „Wij zijn dus uitgetreden uit die bedorven kerkgemeenschap, die ons bleek de valsche kerk te zijn, om de aangebodene hulp op gereformeerde, dat is op bijbelsche grondslagen te kunnen genieten". Ten aansien van die Kaapse Kerk word beklemtoon dat sy die band met die Hervormde Kerk in Nederland wil onderhou: , $N u$ zagen wij, zeggen wij, dat ze vastbesloten had om één te zijn en één te blijven met de Hervormde Kerk van Nederland die wij - en ook de Christelijke Afgescheidene Gereformeerde Kerk in Nederland - houden voor de valsche Kerk, sedert 1816, en die zich vooral bevestigend zoo heeft geopenbaard sedert 1834, en tot op dezen dag". Die verklaring van 1869 sluit: „En met de zoodanigen wenschen wij ook in kerkelijke gemeenskap te leven, en niet met hen die heel of half met die bekende valsche Kerk in Nederland het willen houden". Daar volg ' $n$ wens dat almal hulle hiertoe mag verenig volgens art. 7 NGB.

Bostaande woorde spreek egter 'n taal wat nie misverstaan kan word nie, al klink hulle in hierd:e ekumeniese eeu nogal outyds. Postma het hierdie Verklaring persoonlik onderteken. Dat hy hierby sou uitgegaan het van die leer van pluraliteit van ware kerk pleks van die teenstelling ware/valse kerk volgens art. 29 (soos Van der Vyver, p. 310) beweer, word duidelik deur bostaande sitate weerlê. Ons mag nie, omdat ons vandag daarmee moeilikheid kry of ons daarvoor skaam, die feite van die geskiedenis geweld aandoen nie. 


\section{A. Kuyper en die valse kerk}

Sy kerkbegrip is hoofsaaklik in sy Tractaat van de Reformatie der Kerken (Amsterdam 1884) beskrywe.

Wanneer ons goed wil verstaan wat Kuyper hier oor die valse kerk sê, moet ons eers iets sê oor sy eskatologie. Kuyper het die ewolusie-dogma op die eskatologie toegepas en gestel dat die geskiedenis uitloop op die persoon van die antichris. Vir Calvyn (en Luther) was die pouslike linie die antichris en dit was nie 'n futurologiese superman nie. Calvyn wys daarom die valse kerk aan (bv. Rome) en hy spekuleer nie oor 'n eindtyd met 'n satanskerk nie.

Kuyper het gehoop op 'n politieke koalisie met die Roomse teenoor die liberale rigting en die valse kerk is eintlik 'n toekomsfiguur. „De eigenlijke antichrist (let op die woord ,eigenlijke; v.d.W. !) is alleen hij, in wien het Satan gelukken zal eenmaal zijn bedriegelijken schijn en misdadige vertoning een tijdlang door te zeten. ( . . .) Deze valsche kerk wordt dan bediend door duivelen, maar van wier duivelenaard niets uitkomt, doordien ze zich voordoen als engelen des lichts' (p. 113).

Kuyper beskou dat die valse kerk verskillende grade vertoon, tipies-ewolusionistiese begrip. Hy sê dat toe Luther opgetree het. was daar stellig ' $n$ antichristelike mag in die kerkorganisme; ons vaders van Dordt het nie gesê dat die pous die Antichris was nie. Kuyper teken 'n karikatuur van wat d'e Reformasie insake die valse kerk gestel het asof dit 'n kerk sou wees waar geen enkele gelowige meer in sou wees nie en waarin duiwels sou regeer. 'n Enkele blik in die Institusie van Calvyn en in die Franse Geloofsbelydenis van 1559 kon hom van hierdie karikatuurbeeld verlos het. Die voorwoord van die Dordtse Leerreëls sê van Nederlandse Kerk: ,Want dese Kercke van de Tyrannie des Roomschen Antichrists ende de schrickelicke Afgoderie des Pousdoms door Gods machtighe handt verlost . . . .

Kuyper onderskei vervalste kerke en die absoluut-valse kerk, ,d.i. de voltooide openbaring van de kerk, waarin Satan zijn eindtriomf zal pogen te vieren over den Christus" (p. 115). Hy sê ook: „Wat nog niet vals is, is nog de ware kerk" ( $p$. 161). Hy verstaan "vals" in die eskatologies-absolute sin, 'n kerk waar geen ,spore van die kerk' in feite meer is nie. Dergelike redenerings van Kuyper werk nog vandag deur b.v. in die onlangse debat van P. J. Coetsee in Die Kerkblad met die redakteur van die Hervormer - Kuyper relativeer die begrip ware en valse kerk van die Belydenis. „Dank zij de historische ontwikkeling en de toetsing der verhouding aan haar consequentiën ,staat het thans vast, dat alleen wie zich op het standpunt der Roomsche Hiërarchie plaatst, de absolute tegenstelling tussen die valsche en ware kerk kan handhaven' (De Gemeene Gratie III, p. 271).

Art. 29 pas vir Kuyper in die sestiende eeu. Maar daar was 'n ontwikkeling, 'n ewolusie, 'n historiese proses. Daarom het die pluriformiteit van die kerk ontstaan en ' $n$ mens moet daarmee vandag rekening hou. „Hierdoor nu is eene klove gaan gapen tusschen de in de Belydenis uitgedrukte overtuiging, en de overtuiging die zich later onder den drang van het leven (weer 'n ewolusie-term) gevormd heeft. De Confessie was nog meest uit de eerste periode, en de feite- 
lijke wijziging van overtuiging had eerst in de tweede periode plaats, terwijl de theologen in hun dogmatische uiteenzettingen gemeenlijk niet met de werkelijkheid van den toestand rekenden". Kuyper bely eerlik dat hy in sy leer van die pluriformiteit van die kerk met die belydenis van art. 29 NGB in konflik kom. Hy probeer nie in daardie artikel 'n ander sin lê soos sy epigone soms wel gedoen het nie. Prontuit distaniseer hy hom van art. 29 NGB as outyds. Kuyper is gekritiseer deur Beuker en Ten Hoor, Lindeboom, Van der Schuit, Schilder, en andere.

Die ekumeniese teologie het dieselfde toon as Kuyper aangeslaan met die pleidooi vir 'n pluriformiteit van die kerk en 'n pluriformiteit van die waarheid. Die enigste verskil is dat Kuyper die vryheidsbeginsel wou invoer, 'n laissez faire, laissez aller-praktyk op kerklike gebied, terwyl die ekumeniese beweging 'n institutêre eenheid wil vorm wat oor die kakofonie van rigtings uitgesprei word.

\section{Die ,Beding' van die vereniging van 1892}

By die Totius-herdenking is herinner aan die Afgeskeidenis (De Christelijk Gereformeerde Kerk) en die Dolerendes (De Nederduitsch Gereformeerde Kerk) wat in 1892 verenig het. Die twee strominge sou ook in Totius, skoonseun van die afgeskeie Postma en leerling van Kuyper, ineengevloei het.

Daar was in 1892 van die kant van die Afgeskeidenis groot besware teen die Dolerendes se kerkbegrip. Die Afskeiding het immers die Hervormde Kerk volgens die Belydenis art. 27-29 getipeer. Die gedagte van pluriformiteit van die kerk was aan die navolgers van Hendrik de Cock volkome vreemd. Die redenering dat waar nog gelowiges is, daar 'n ware sigbare kerk voorkom (vgl. Kuyper) is deur die Afgeskeidenes bestry.

R. H. Bremmer (Geref. Kerkblad voor Ov. en Gelderland I, no. 48, 4 Junie 1949) noem Herman Bavinck ' $n$ man ,,met zijn altijd tot synthese neigende geest”. Hy het gesê: „Wij zeggen: wij zijn in 1834 tot de belijdenis wedergekeerden en zijn toen door de valsche kerk uitgeworpen, van haar uitgegaan. $Z_{i j}$ d.w.s. die dolerendes; v.d.W.) zeggen: wij hebben, als zijnde steeds hetzelfde lichaam gebleven, steeds dezelfde belijdenis gehad en gehouden, en wij zijn rechtens nooit los van haar geweest, en toen door Gods genade onze oogen weer voor die belijdenis opengingen, hebben wij de valsche besturen en reglementen en heel 't Genootschap uitgeworpen en van ons gedaan" (De Bazuin 1888, no 31). Die verskil tussen Afgeskeidenes en Dolerendes is gebagatelliseer. Die leer van die pluriformiteit van die kerk het die veruitwendiging van De Gereformeerde Kerken in Nederland aangehelp, hoewel daar skynbaar 'n groot politieke bloei was van die ,gereformeerde volksdeel'. K. Schilder het in die dertiger jare weer 'n klip in die bos gegooi toe hy Kuyper se leer oor die kerk bevraagteken het.

Die feit dat die sinodaal Geref. Kerke die Ekumeniese Beweging na die oorlog gesteun het, kan as bewys dien dat hulle 'n reformasie in die rigting van die Afskeiding wou verhoed. Die feit dat die stryd tydens die veertiger jare rondom die verbond uitgebreek het, 
mag die feit dat die leer oor die kerk ook in geding was, nie verberg nie. In die Akte van Vrijmaking is nadruklik op art. 29 teruggegryp.

Dit is ' $n$ feit dat tydens die Vereniging van 1892 nadruklik gesê is dat die dolerende beskouing oor die Hervormde Kerk nie juis is nie. Die Afgeskeidenis het immers as voorwaarde gestel: „als, wat de verhouding tot de Ned. Herv. Kerk betreft, dit wederzijds worde uitgesproken, dat verbreking van de Kerkelijke gemeenschap met de besturen van de Ned. Herv. Kerk niet alleen, maar ook met de leden in corporatieven en plaatselijke zin, door Gods Woord en de Geref. Belijdenis geboden en dus noodzakelijk is". Die gekursiveerde woorde het die sinode in die oorspronklike voorstel van Van Andel/Bavinck ingevoeg. Daarmee is in feite uitgespreek dat 'n plaatselike Herv. gemeente nie volgens art. 28 en 29 NGB ' $n$, ware kerk' genoem kon word nie. Die feit dat L. Lindeboom verklaar het dat hy ook vir die voorstel wat net van „maar ook de leden" gepraat het, sou gestem het, spreek duidelike taal.

Die ,Beding' het onmiddellik na die Vereniging net soos die Verklaring van 1869 in die doofpot tereg gekom. Toe ek dit in 1954 wou publiseer, moes ek dit uit die Handelinge van die afgeskeie sinode van 1891 opdiep.

\section{Slot}

Ek wou die feitlike stand van sake skets. Tenslotte was die Afgeske:e Kerk die moederkerk van die Gereformeerde Kerk in SuidAfrika. Iaasgenoemde Kerk het ook die reg om te weet wat aangegaan het sodat hy sy eie papiere kan beoordeel.

Die vraag kan gestel word of ook in Suid-Afrika die tyd nie aangebreek het dat die werwende (en nie afstotende) waarde van art. 29 NGB in die oog gekry moet word nie. Die susterskerkementaliteit en moenieseermaaknie-houding kan vrede en aangename rus bevorder, maar kan tewens 'n geleider wees vir 'n ingeslape christendom wat immobiliteit vertoon en geen werwende krag besit nie, omdat alle fierheid aan toleransie en relativering ten prooi geval het.

Ons het vandag Calvyn se gloed van oortuiging nodig toe hy aan Sadoletus geskrywe het: „Mense is gewoond om my te verwyt dat ek my van die kerk afgeskei het. Dog wat dit betref het ek 'n goeie gewete. $\mathrm{Hy}$ is tog nie 'n droster nie wat wanneer hy sien dat die soldate na alle kante vlug en hul poste verlaat - die vaandel van die veldheer weer optel en hulle na hul posisies terugroep nie?" (1539).

Gelewer vorr die GTV Pretoria 28.2.1977.

NOTA.

Dr. C. v. d. Waal is predikant van die Vrye Geref. Kerk, Pretoria en bekend vir sy skerp toepassing van art. 29 NGB op kerkstrukture om daarmee die „adres van die ware kerk” te bepaal. Vanweë die 
korrespondensie met die GKN kon die GKSA nie die ware kerk wees nie. V.d.W. praat van die CAGK as "moederkerk" van die GKSA. Die vraag is of art. 29 NGB so geobjektiveerd en sinodaal-institusioneel in 1563 bedoel was en vandag tereg so toegepas kan word onder gereformeerde gesindte. Kan dit, gesien die plasing ná art. 28 NGB anders as op die kerk, d.w.s. die gemeente of plaaslike kerk, bedoel wees? Die universele kerk (art. 27 NGB) word immers in die plaaslike kerk sigbaar en sinodale verbande is vorme van kerkregering en nie van kerk-wees nie. Die drie kenmerke van art. 29 NGB kan tog net in die „plaaslike” kerk konkretiseer. Dan lyk dit asof „,valse kerk" binne 'n gereformeerd kerkverband kan voorkom en gelowiges moet dit beoordeel (art. $28 \mathrm{NGB}$ ). - Red. 